\title{
BMJ Open Depressive symptoms in adults in rural and urban regions of Canada: a cross- sectional analysis of the Canadian Longitudinal Study on Aging
}

\author{
Philip D St John (1) , ${ }^{1}$ Verena Menec, ${ }^{2}$ Robert Tate (D) , ${ }^{3}$ Nancy E Newall, ${ }^{4}$ \\ Denise Cloutier, ${ }^{5}$ Megan O'Connell (iD ${ }^{6}$
}

To cite: St John PD, Menec V, Tate $\mathrm{R}$, et al. Depressive symptoms in adults in rural and urban regions of Canada: a cross-sectional analysis of the Canadian Longitudinal Study on Aging. BMJ Open 2021;11:e048090. doi:10.1136/ bmjopen-2020-048090

- Prepublication history for this paper is available online. To view these files, please visit the journal online (http://dx.doi. org/10.1136/bmjopen-2020048090).

Received 16 December 2020 Accepted 30 September 2021

Check for updates

(c) Author(s) (or their employer(s)) 2021. Re-use permitted under CC BY-NC. No commercial re-use. See rights and permissions. Published by BMJ.

For numbered affiliations see end of article.

Correspondence to Dr Philip D St John; pstjohn@hsc.mb.ca

\section{ABSTRACT}

Objectives Previous studies on depression in rural areas have yielded conflicting results. Features of rural areas may be conducive or detrimental to mental health. Our objective for this study was to determine if there are ruralurban disparities in depressive symptoms between those living in rural and urban areas of Canada.

Design We conducted a cross-sectional analysis of a prospective cohort study, which is as representative as possible of the Canadian population-the Tracking Cohort of the Canadian Longitudinal Study on Aging. For this cohort, data were collected from 2010 to 2014. Data were analysed and results were obtained in 2020.

Participants 21241 adults aged 45-85.

Measures Rurality was grouped as urban ( $n=11772)$; peri-urban $(n=2637)$; mixed ( $n=2125$; postal codes with both rural and urban areas); and rural ( $n=4707)$. Depressive symptoms were measured using the 10item Center for Epidemiological Studies-Depression. We considered age, sex, education, marital status and disease states as potential confounding factors.

Results The adjusted beta coefficient was -0.24 (95\% Cl -0.42 to $-0.07 ; p=0.01)$ for rural participants, $-0.17(95 \% \mathrm{Cl}-0.40$ to $0.05 ; \mathrm{p}=0.14)$ for peri-urban participants and $-0.30(95 \% \mathrm{Cl}-0.54$ to $-0.05 ; \mathrm{p}=0.02)$ for participants in mixed regions, relative to urban regions. Risk factors associated with depressive symptoms were similar in rural and urban regions.

Conclusions The small differences in depressive symptoms among those living in rural and urban regions are unlikely to be relevant at a clinical or population level. The findings do suggest some possible approaches to reducing depressive symptoms in both rural and urban populations. Future research is needed in other settings and on change in depressive symptoms over time.

\section{INTRODUCTION}

Depression is a common issue facing people-the life time cumulative prevalence in Canada is about $12 \% .^{1}$ Depression and depressive symptoms are associated with reduced life satisfaction, ${ }^{2}$ higher healthcare service use ${ }^{3}$ and poor functional status. ${ }^{34}$ In addition, cohort studies of older adults have
Strengths and limitations of this study

- We used a nationwide dataset intended to be as representative as possible of the Canadian population.

- We considered a gradient in rurality from large urban centres to rural areas.

- The 10-item Center for Epidemiological StudiesDepression is a reliable and valid measure of depressive symptoms, but not of major depression.

- We were only able to consider one measure of rurality, while different measures of rurality exist.

Both rural and urban areas are highly heterogeneous.

shown that depressive symptoms predict mortality. ${ }^{5-7}$ There is also some evidence that depressive symptoms predict poor health outcomes as a gradient across the spectrum of symptoms, and this may not be limited to only those who have depressive symptoms above a certain threshold. ${ }^{8}$ Understanding factors that predict depressive symptoms may be important to identify modifiable risk factors for depressive symptoms, which may be amenable to social, psychological and clinical interventions at both individual and population levels. Understanding rates of depressive symptoms in various populations is also important in establishing the need for services in those communities.

It has long been postulated that urbanisation and industrialisation disrupt traditional relationships resulting in displaced personal relations. Furthermore, institutions subsequently evolved to meet societal needs rather than to individual requirements. ${ }^{9}$ This led to speculation that mental health deteriorated with urbanisation. However, depressive symptoms may be positively and negatively affected by a rural residence in different ways. First, distance to friends and family may be greater in rural areas than in urban areas, as may be distances to social and health services. ${ }^{10} 11$ 
Second, the low population density may be more socially isolating for people living in rural and remote locations. ${ }^{12-14}$ Third, educational attainment and income may be lower in rural areas than in urban areas ${ }^{1516}$; and lower educational attainment and lower income are strongly associated with depressive symptoms. ${ }^{17-19}$ Fourth, there may be differences in health status between rural and urban populations. ${ }^{20-22}$ Some research reports higher rates of vascular disease, ${ }^{23}$ dementia $^{24}$ and substance misuse $^{25}$ in rural areas, although these reports are far from conclusive. Fifth, there may be migration effects, with unwell individuals migrating to larger centres to seek social and healthcare; or conversely of well people and youth seeking employment and education. ${ }^{26} 27$ In combination with ageing in place, this could in turn lead to higher proportions of older adults in rural areas. On the positive side, the social networks in rural areas may be larger and/or more consistent over time than in urban areas. ${ }^{28}$ There may also be more sense of connection to a community in a rural area than an urban one. ${ }^{122930}$ Finally, there may be social and economic changes to both rural and urban areas that may influence depressive symptoms.

Thus, the study of depressive symptoms in rural regions is complicated. First, the epidemiology of these associations is complex, ${ }^{31}$ with multiple interacting risk factors operating over long time horizons. In some populations, competing risks from different outcomes (such as mortality) complicate analyses because of loss to follow-up prior to the onset of depressive symptoms. ${ }^{32}$ Second, studying the effect of a rural residence on health is also complicated. People may migrate between regions, ${ }^{26} 2733$ and the exposure to effects may vary at different points in the life course. Rural regions are heterogeneous, and the effect of exposures may differ between rural regions, and indeed between urban regions. ${ }^{34}$ Third, the geographical level of effect (local, national or state/provincial) may be difficult to ascertain. For instance, the effect of inequality within a small town or rural municipality may be less relevant than the effect of inequality within a state or society. Finally, research into rural populations is costly and difficult to undertake due to travel times and distance from academic centres.

These difficulties may explain the differing findings in previous studies of rurality and the risk of depression. Some studies report no major rural-urban differences in depressive symptoms, ${ }^{35-37}$ while others report lower rates of depression in urban areas, ${ }^{38}$ or lower rates of depression in rural areas. ${ }^{39}$ This research has recently been summarised in a meta-analysis, which reports that a rural residence is associated with depressive symptoms in Global Southern countries-particularly those that are undergoing rapid urbanisation. ${ }^{40}$ However, in Global Northern countries, they noted higher rates of depression among urban residents than among rural residents.

To address some of these issues, we have conducted a cross-sectional analysis of the first wave of a populationbased cohort study - the Canadian Longitudinal Study on Aging (CLSA). The specific objectives were:
1. To determine the prevalence of depressive symptoms in rural adults aged $45-85$.

2. To determine if rural residence is associated with increased depressive symptoms after accounting for the effect of potential confounding factors.

3 . To determine if the risk factors for depressive symptoms are different in rural versus urban populations.

\section{MATERIALS AND METHODS}

\section{Study sample}

The CLSA is a population-based cohort study, which is ongoing. ${ }^{41-44}$ We used a cross-sectional sample from the initial survey wave of the 'tracking cohort' $(\mathrm{N}=21241)$. The CLSA is composed of two related cohorts-the 'tracking cohort' and the 'comprehensive cohort'. The tracking cohort is the group which is intended to be generalisable to the Canadian population, as opposed to the more detailed larger 'comprehensive' cohort which includes only those in proximity to one of the clinical data collection sites, all of which are in urban settings. Participants for the tracking cohort were recruited by the CLSA from the general Canadian population through the Canadian Community Health Survey on Healthy Aging, provincial healthcare registration databases and random digit dialling. The baseline data from all participants were collected between 2010 and 2014, using computerassisted telephone interviewing. The tracking cohort is intended to be as generalisable as possible to the Canadian population of $2008 .{ }^{45}$ The age range is from 45 to 85. Due to the time between the initial sampling frame time and the survey conduct, there was a very small number of participants who were 44 , or who were age 85-89. These people were included in the analyses. The sampling frame for the tracking cohort was complex, but based on Statistics Canada geographical classifications. ${ }^{46}$ All dwellings within the same Census dissemination area block $(\mathrm{CB})$ identified as either urban or rural were grouped together. In each province, clusters of CBs were created having a fixed number of dwellings with a minimum number of people in the 75-84 and 85 or over age groups. Clusters were composed entirely of urban or rural CBs and could not cross provincial boundaries. ${ }^{45}$ This sampling strategy ensures accurate categorisation of rurality as well as an adequate sample size for rural analyses. Excluded from the CLSA sampling frame were people residing in the three territories and some remote regions, or residing on federal First Nations reserves and other First Nations settlements in the provinces, as well as full-time members of the Canadian Armed Forces, individuals living in institutions, individuals holding a temporary visa or having transitional health coverage, individuals unable to respond in English or French, and individuals with cognitive impairment, at time of recruitment. The flow of participants has been previously reported. $^{46}$ 
Table 1 Definitions of rural and urban in the CLSA

\begin{tabular}{|c|c|c|c|}
\hline $\begin{array}{l}\text { Definition for } \\
\text { analyses }\end{array}$ & Definition in CLSA & $\begin{array}{l}\text { Sample } \\
\text { size }\end{array}$ & Definition \\
\hline Rural & Rural & 4707 & $\begin{array}{l}\text { The area that remains after the delineation of urban areas which have } \\
\text { been delineated using current census population data. }\end{array}$ \\
\hline Mixed & $\begin{array}{l}\text { Postal code link to } \\
\text { dissemination area }\end{array}$ & 2125 & $\begin{array}{l}\text { This is assigned if a postal code covers a large area and it is a mixture of } \\
\text { urban and rural area. }\end{array}$ \\
\hline Peri-urban & Urban fringe & 445 & $\begin{array}{l}\text { All small urban areas within a CMA or CA that are not contiguous with } \\
\text { the urban core of the CMA or CA. }\end{array}$ \\
\hline Peri-urban & $\begin{array}{l}\text { Urban population centre } \\
\text { outside CMA and CA }\end{array}$ & 1888 & $\begin{array}{l}\text { Built up areas that are not contiguous within or contiguous with the } \\
\text { urban core of the CMA or CA. }\end{array}$ \\
\hline Peri-urban & Secondary core & 304 & $\begin{array}{l}\text { A population centre within a CMA that has at least } 10000 \text { persons and } \\
\text { was the core of a CA that has been merged with an adjacent CMA. }\end{array}$ \\
\hline Urban & Urban & 11772 & $\begin{array}{l}\text { A large urban area around which a CMA or a CA is delineated. } \\
\text { The urban core must have a population (based on the previous census) } \\
\text { of at least } 50000 \text { persons in the case of a CMA, or at least } 10000 \\
\text { persons in the case of a CA. }\end{array}$ \\
\hline
\end{tabular}

The definitions 'urban fringe', 'urban population center outside CMA and CA', and 'secondary core' are defined as separate categories in the CLSA, but are grouped together as one category of 'peri-urban' in this study.

CA, census agglomeration; CLSA, Canadian Longitudinal Study on Aging; CMA, census metropolitan area.

\section{Definition of rural}

There are numerous definitions of rurality, and the definition used can influence the findings. ${ }^{47}$ We used the definitions of rurality used in the CLSA sampling frame. These are similar to the definitions used historically in the Canadian Community Health Survey ${ }^{48}$ and the 2006 census. A detailed description is provided in the 2006 Census Guide. ${ }^{49}$ To summarise, geographical definitions are based on the size of the community. A census metropolitan area (CMA) or a census agglomeration (CA) is formed by one or more adjacent municipalities centred on a population centre (known as the core). A CMA must have a total population of at least 100000 , of which 50000 or more must live in the core. A CA must have a core population of at least 10000 . To be included in the CMA or CA, other adjacent municipalities must have a high degree of integration with the core, as measured by commuting flows derived from previous census place of work data. ${ }^{49}$ The definitions of rurality, and the sample size within each category are shown in table 1 . For these analyses, we collapsed the different definitions used in the CLSA into four categories: rural $(n=4707)$ versus mixed (which we defined as the 'postal code link to dissemination area' variable; $\mathrm{n}=2125$ ) versus peri-urban ('urban fringe and secondary urban sites'; n=2637) versus urban ('urban core'; n=11 772). These definitions allow consideration of increasing rurality across an urban to rural spectrum. The description of the sampling strategy, sample characteristics and categorisation of rurality are the same as we have used in other analyses of this data set, ${ }^{5051}$ in order to ensure consistency.

\section{Measure of depressive symptoms}

The 10-item Center for Epidemiological Studies Depression Scale (CES-D-10) ${ }^{52}$ is an abbreviated version of the full CES-D, ${ }^{53}$ with comparable test characteristics. ${ }^{54} 55$ It is a widely used, reliable and valid measure of depressive symptoms. ${ }^{45}$ However, it is not a measure of clinically diagnosed major depression. For our primary analyses, we considered the CES-D-10 as a continuous measure, since the CES-D-10 predicts adverse outcomes across the entire range of the instrument, including within the normal range. ${ }^{656}$ The range of possible scores on the CES-D-10 is 0-30. As a sensitivity analysis, we also considered the CES-D-10 as a dichotomous variable, using a cutoff point of 10 or higher, which has been suggested to indicate the presence of depressive symptoms in clinical samples. 525758

\section{Other measures}

We considered a number of potential confounding factors and interactions in our analyses. Demographic factors such as age, were self-reported. We considered sex in two categories (male vs female), education in four categories (less than secondary school graduation, secondary school graduation but no postsecondary education, some postsecondary education and postsecondary degree/ diploma), individual income in categories of $<\$ 20000$, $\$ 20-49$ 999, \$50-99 999, \$100-1 49999 and >\$150 000, all in Canadian dollars; living situation in two categories (alone vs not alone); and marital status in categories of never married, married/common-law, separated, divorced and widowed. ${ }^{59}$ These categories were chosen based on the categorisations in the CLSA. We also considered self-reported chronic conditions that are less likely to be subject to surveillance bias ascribable to differing degrees of access to healthcare in rural areas compared with urban $\operatorname{areas}^{60}$ : chronic obstructive pulmonary disease, stroke or cerebrovascular attack, ischaemic heart disease, cancer (any site), osteoarthritis and cataracts. ${ }^{61}$ 
These were measured with the question: 'Now I'd like to ask about any chronic health conditions which you may have. We are interested in "longterm conditions" which are expected to last, or have already lasted 6 months or more and that have been diagnosed by a health professional. Has a doctor ever told you that you have ...?'

\section{Statistical analysis}

To account for the complex sampling design, the CLSA has calculated weights to create prevalence estimates that represent the Canadian population (inflation weights, also known as trimmed weights) and for estimating associations (analytic weights). ${ }^{43}$ Analytic weights are inflation weights that have been rescaled to sum to sample size within each province. These were provided in the CLSA data set. Analyses considered the analytic weights, while descriptive statistics considered the trimmed weights. We used the sample weights originally provided by the CLSA, which reflect the Canadian population at the time of initial sampling in 2008/2009. We excluded participants for whom data were missing for a rural residence or for depressive symptoms. In statistical models, we also excluded those with missing variables on the confounding factors.

We conducted bivariate analyses for the outcome of CES-D-10 and each of the independent variables, using Student's t-tests for continuous variables, analysis of variance for continuous variables considering more than two groups, and $\chi^{2}$ tests for categorical variables. We constructed linear regression models with the outcome of CES-D-10. We constructed a series of models beginning with adjustment for age and sex, then for demographic factors, and finally for health-related factors. Per CLSA protocol, ${ }^{45}$ we considered analytic weights, and included province of residence in all regression models (province is not displayed in the tables). Income had a fairly large number of missing variables $(\mathrm{N}=1370)$, who were excluded from the models including income. Otherwise, there were few participants $(\mathrm{N}=80)$ who had missing data on any of the other covariates in the full model, who were also excluded from the regression model. To determine if there were interactions between a variable of interest and rural residence, we constructed regression models with the main effects for that variable and rurality, as well as the interaction term of that variable and rurality. We noted an interaction between widowed status and living in a periurban region, as well as a diagnosis of cancer and living in a mixed region. However, the effect size was small, and including the interaction term did not greatly affect the model fit. We therefore present the model without interactions. Finally, we checked models for violations of the model assumptions. We performed the statistical analyses and obtained the results in 2020. We conducted all statistical analyses with SAS V.9.4.

\section{Patient and public involvement}

There were no participants involved in the development of this study. The results of the CLSA are disseminated to the public through websites and webinars.
RESULTS

The baseline characteristics of the sample are shown in table 2. This table also shows the prevalence of depressive symptoms. These results consider the CLSA trimmed weights and are broadly reflective of the Canadian population. Those living in rural areas had lower levels of educational attainment, and lower household income than those living in urban and peri-urban areas. Differences in age and sex between rural and urban areas are difficult to comment on, given that the sampling frame was stratified on these variables. The mean CES-D-10 scores in rural, peri-urban, mixed and urban areas are shown in figure 1 . There were very minor differences in depressive symptoms between these areas, and only the difference between rural group was statistically significant from the others $(\mathrm{p}=0.04)$.

The results of the linear regression models are shown in table 3. There was a statistically significant difference in the CES-D-10 between those residing in rural regions, and those residing in urban regions $(p=0.04)$. However, this difference was extremely small-only a fraction of a point on the CES-D-10. The statistical significance was maintained after adjusting for a wide variety of healthrelated and social factors $(\mathrm{p}=0.01)$. However, the absolute differences remained very small.

In all areas, some important factors emerged as predictors of depressive symptoms. Advancing age was associated with fewer depressive symptoms, but the magnitude of this effect was small. Females had higher CES-D-10 scores than males did. Married people had lower CESD-10 scores than the reference group (separated individuals). There was also a strong gradient effect seen across income groups, with those in the highest income category having the lowest CES-D-10 scores. A similar effect was observed for educational attainment, with those in the lowest education category having the highest CES-D-10 scores. Finally, most chronic conditions were associated with depressive symptoms.

The results of logistic regression models, categorising the CES-D-10 into those with and without depressive symptoms, were very similar (table 4 ). In these models, we noted no statistically significant differences in the odds of depressive symptoms between rural, mixed, periurban and urban areas. Factors that predict the presence of depressive symptoms were otherwise similar in both models.

\section{DISCUSSION}

We conducted a cross-sectional analysis of a population-based cohort study and found only minimal rural-urban differences in depressive symptoms. We feel that these differences are not relevant at a clinical or population level. We also noted potential risk factors associated with depressive symptoms. First, we noted that married participants had lower depression scores. This is consistent with some other studies, which noted the same effect. ${ }^{62-64}$ However, the effect 
Table 2 Baseline characteristics of participants

\begin{tabular}{|c|c|c|c|c|}
\hline Characteristic & $\begin{array}{l}\begin{array}{l}\text { Rural } \\
(n=4707) \\
\% \dagger\end{array} \\
\%\end{array}$ & $\begin{array}{l}\text { Mixed }^{*} \\
(n=2125) \\
\% \dagger\end{array}$ & $\begin{array}{l}\text { Peri-urban } \\
(n=2637) \\
\% \dagger\end{array}$ & $\begin{array}{l}\text { Urban } \\
(n=11 \text { 772) } \\
\% \dagger\end{array}$ \\
\hline Male sex & 47.2 & 45.0 & 47.8 & 49.2 \\
\hline \multicolumn{5}{|l|}{ Age (years) } \\
\hline $44-54$ & 36.5 & 33.8 & 34.8 & 37.3 \\
\hline $55-64$ & 31.4 & 33.2 & 34.3 & 30.0 \\
\hline $65-74$ & 21.5 & 21.1 & 18.0 & 19.2 \\
\hline $75-89$ & 10.6 & 12.0 & 12.9 & 13.5 \\
\hline \multicolumn{5}{|l|}{ Education } \\
\hline Less than secondary school graduation & 10.2 & 10.3 & 9.0 & 5.6 \\
\hline $\begin{array}{l}\text { Secondary school graduation, no postsecondary } \\
\text { education }\end{array}$ & 15.7 & 14.7 & 14.3 & 11.4 \\
\hline Some postsecondary education & 7.6 & 9.4 & 9.4 & 7.0 \\
\hline Postsecondary degree/diploma & 66.1 & 65.5 & 66.8 & 75.6 \\
\hline$\geq 1$ required question not answered & 0.3 & 0.1 & 0.5 & 0.5 \\
\hline \multicolumn{5}{|l|}{$\begin{array}{l}\text { Number of people living in household (excluding } \\
\text { participant) }\end{array}$} \\
\hline Living alone & 13.0 & 16.1 & 16.9 & 20.0 \\
\hline Living with 1 person & 58.2 & 59.0 & 53.4 & 46.9 \\
\hline Living with 2 people & 14.0 & 12.8 & 15.7 & 15.9 \\
\hline Living with 3 people & 10.0 & 8.1 & 9.5 & 11.8 \\
\hline Living with 4 people & 3.1 & 2.9 & 3.0 & 4.0 \\
\hline Living with $\geq 5$ people & 1.7 & 1.1 & 1.5 & 1.6 \\
\hline \multicolumn{5}{|l|}{ Marital status } \\
\hline Married/common-law & 80.1 & 78.7 & 76.2 & 70.2 \\
\hline Never married & 6.5 & 5.1 & 5.7 & 9.4 \\
\hline Widowed & 6.4 & 7.6 & 7.9 & 7.8 \\
\hline Divorced & 5.1 & 6.5 & 7.3 & 9.8 \\
\hline Separated & 1.9 & 2.0 & 2.8 & 2.7 \\
\hline Refused to answer & 0.0 & 0.0 & 0.1 & 0.0 \\
\hline \multicolumn{5}{|l|}{ Individual income } \\
\hline$<\$ 20000$ & 5.0 & 5.1 & 5.3 & 5.0 \\
\hline$\$ 20000-\$ 49999$ & 27.0 & 27.2 & 24.9 & 20.5 \\
\hline$\$ 50000-\$ 99999$ & 36.4 & 35.1 & 34.1 & 32.9 \\
\hline$\$ 100000-\$ 149999$ & 17.0 & 15.5 & 18.2 & 18.4 \\
\hline$\geq \$ 150000$ & 9.7 & 11.4 & 11.9 & 16.9 \\
\hline Do not know/no answer/refused & 4.8 & 5.7 & 5.5 & 6.2 \\
\hline \multicolumn{5}{|l|}{ Chronic conditions } \\
\hline COPD or chronic changes in lungs due to smoking & 5.6 & 6.8 & 5.6 & 5.7 \\
\hline Stroke or cerebrovascular accident & 1.6 & 1.3 & 2.1 & 1.5 \\
\hline Cataracts & 18.6 & 21.6 & 19.8 & 20.3 \\
\hline Cancer & 12.5 & 12.4 & 14.2 & 13.8 \\
\hline Heart disease & 8.5 & 8.0 & 9.5 & 9.5 \\
\hline Osteoarthritis & 26.0 & 25.9 & 24.6 & 23.7 \\
\hline \multicolumn{5}{|l|}{ Depression $\ddagger$} \\
\hline Depressive symptoms (score $\geq 10$ ) & 16.3 & 17.1 & 17.1 & 17.1 \\
\hline
\end{tabular}




\begin{tabular}{|c|c|c|c|c|}
\hline Characteristic & $\begin{array}{l}\text { Rural } \\
(n=4707) \\
\% \dagger\end{array}$ & $\begin{array}{l}\text { Mixed }^{*} \\
(n=2125) \\
\% \dagger \\
\end{array}$ & $\begin{array}{l}\text { Peri-urban } \\
(n=2637) \\
\% \dagger\end{array}$ & $\begin{array}{l}\text { Urban } \\
(n=11772) \\
\% \dagger\end{array}$ \\
\hline$\geq 2$ missing answers & 0.2 & 0.3 & 0.6 & 0.4 \\
\hline CES-D-10 score (mean $(95 \% \mathrm{Cl}))$ & $5.3(5.1$ to 5.4$)$ & 5.5 (5.2 to 5.8$)$ & 5.5 (5.2 to 5.7$)$ & 5.5 (5.4 to 5.6$)$ \\
\hline
\end{tabular}

*Area with postal code linked to dissemination area, a mixture of both urban and rural.

†Unless otherwise indicated.

†Range of possible scores on CES-D-10 is $0-30$.

CES-D-10, 10-item Center for Epidemiologic Studies Depression Scale; COPD, chronic obstructive pulmonary disease.

of marital status on depressive symptoms may differ between men and women, ${ }^{62} 63$ and may depend on the satisfaction with one's partner, and/or perceived marital quality. ${ }^{62}$ Second, we noted an effect of income on depressive symptoms, which appeared to have a gradient effect, with higher levels of depressive symptoms among those with lower incomes. While this is consistent with many other epidemiological studies, ${ }^{18}{ }^{19}$ the magnitude of this effect is quite large. Some of these factors, such as education, chronic illness and low income, may be partly modifiable. Further prospective research is needed into these factors.

There are both strengths and limitations to our analyses. First, the CLSA is a large population-based study intended to be as representative as possible of the Canadian population. ${ }^{45}$ However, the exclusion of some groups (active members of the Canadian Armed Forces, and First Nations) may affect the findings, since they may differentially reside in urban or rural regions, and have different levels of depressive symptoms. A second strength is the consideration of a gradient in rurality from large urban centres to rural areas. Third, the CES-D-10 is a reliable and valid measure of depressive symptoms. ${ }^{45} 55$ However, it is a

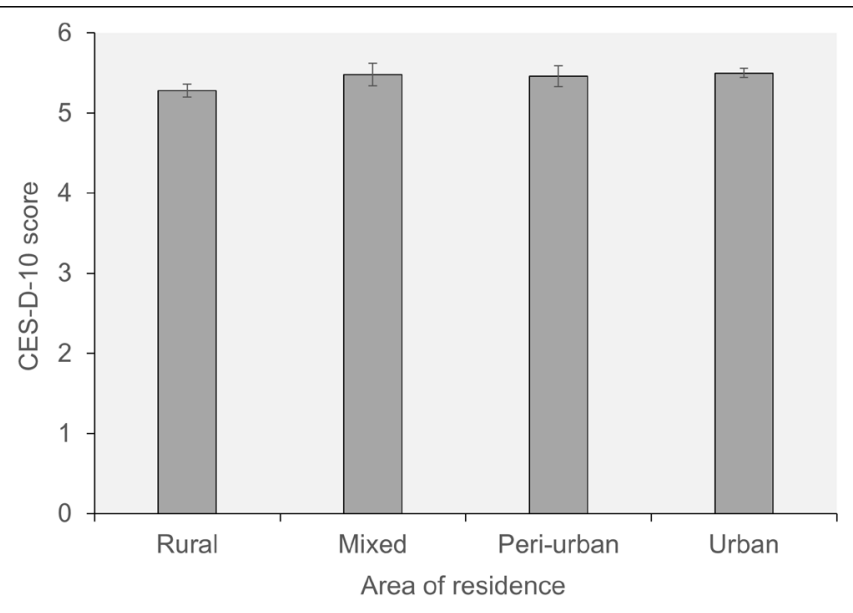

Figure 1 Mean score \pm SE of the mean on the 10-item Center for Epidemiological Studies Depression Scale (CES$\mathrm{D}-10$ ) (maximum possible score is 30 ). measure of depressive symptoms, not of major depression. It is possible that there are rural-urban differences in major depression, which we were unable to study. Other limitations include our ability to consider only one measure of rurality, while there are many different measures of rurality. ${ }^{47}$ Third, both rural and urban areas are highly heterogeneous. ${ }^{65}$ Differences between rural areas may be important, and the factors that may predict these differences could be important. Fourth, rural-urban differences may be dependent on the general societal context. For instance, the recent economic decline in rural America may not be as evident in rural Canada. ${ }^{66}{ }^{67}$ Finally, we did not study change in residential setting, and the effect of this on depressive symptoms. As future waves of data collection occur, we hope to address this over time.

Our findings are consistent with other studies of depression and depressive symptoms. In a recent metaanalysis, Purtle et al found that there were minimal ruralurban differences in depressive symptoms between those living in Global Northern countries ${ }^{40}$; unlike in Global Southern countries. However, there were relatively few studies included in that meta-analysis, and the authors noted the need for further study. ${ }^{40}$ Also, our findings are consistent with older data from an older population in Manitoba, ${ }^{35}{ }^{36}$ but somewhat different from a report from Quebec. ${ }^{38}$ There, it was noted that depressive symptoms were lower in Montreal than in rural regions of the province.

Our findings do suggest some possible approaches to reducing depressive symptoms in both rural and urban populations. Since there is a strong gradient across income and educational attainment, minimising social gradients may be important in reducing gradients in depressive symptoms. As well, we noted an association between chronic illness and depressive symptoms. Ensuring access to high quality healthcare may be important to reduce depressive symptoms, wherever people live. This may be more challenging in rural areas, where travel times are longer, population densities are smaller and attracting healthcare providers may be more difficult. ${ }^{1068-71}$ Future research is needed in other settings, addressing some of the limitations in our study, and change in depressive symptoms over time. 


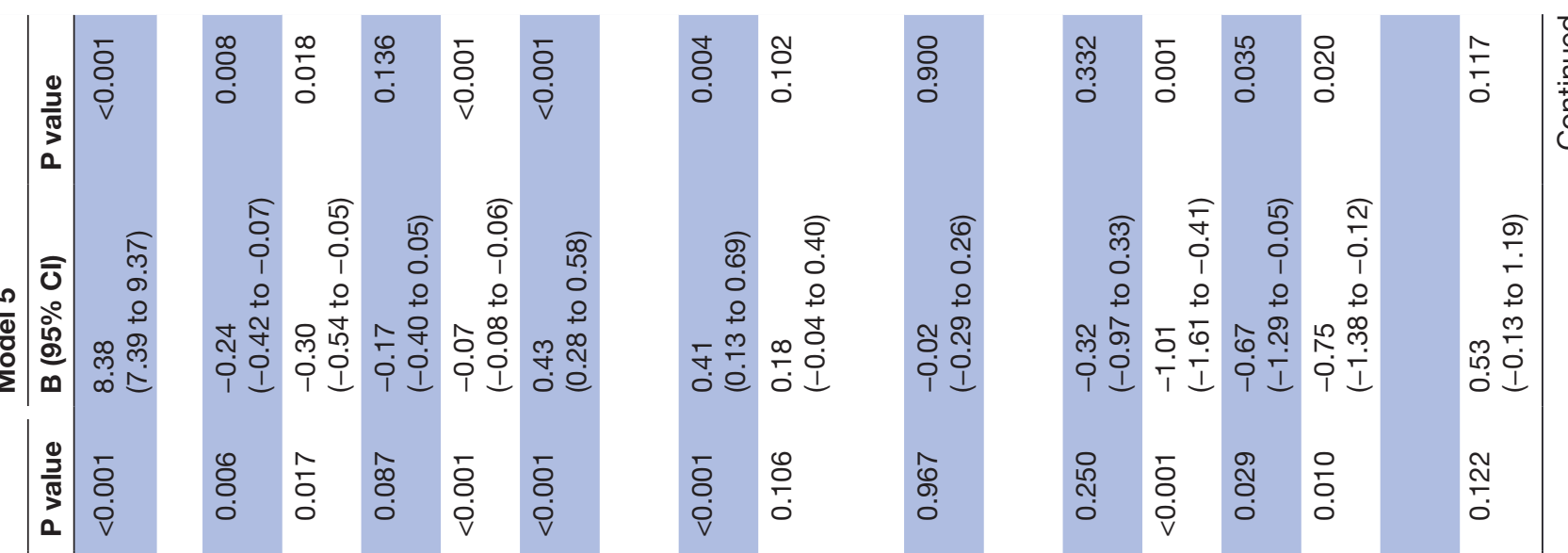



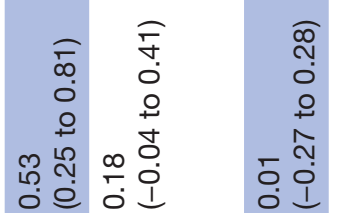

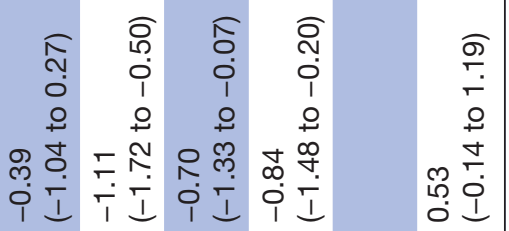

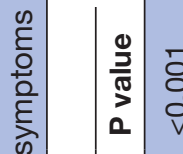

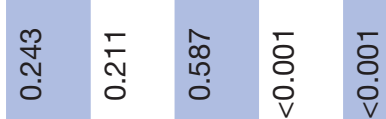

$\begin{array}{ll}\overline{0} & \overline{8} \\ 0 & 0 \\ \text { v } & \text { v }\end{array}$

옴.

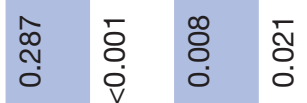

ஜ̊

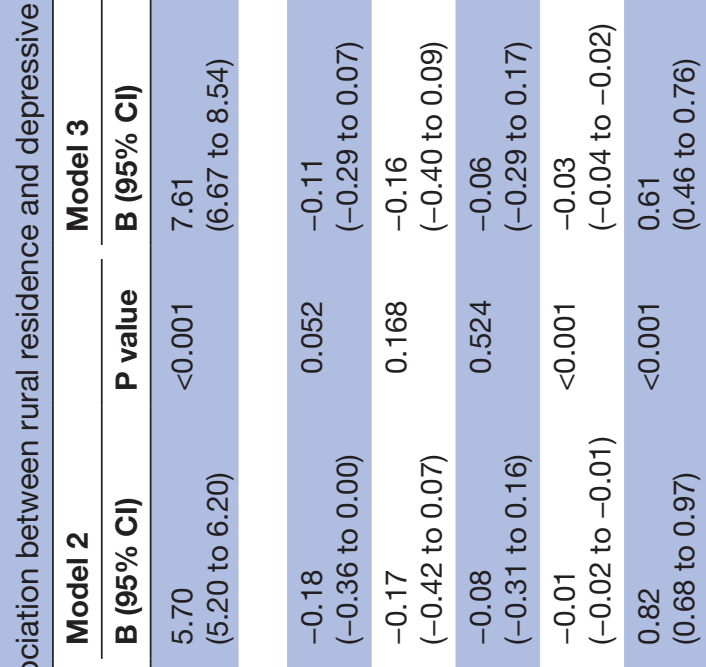

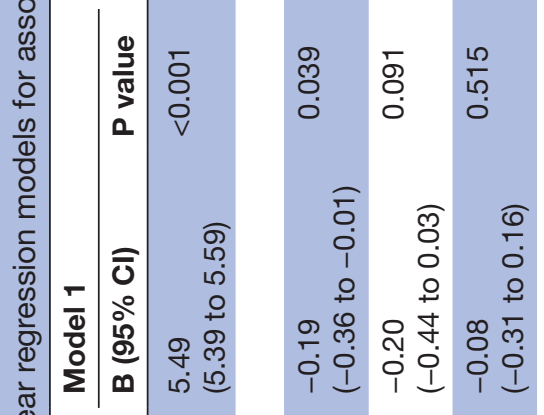

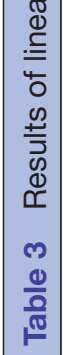
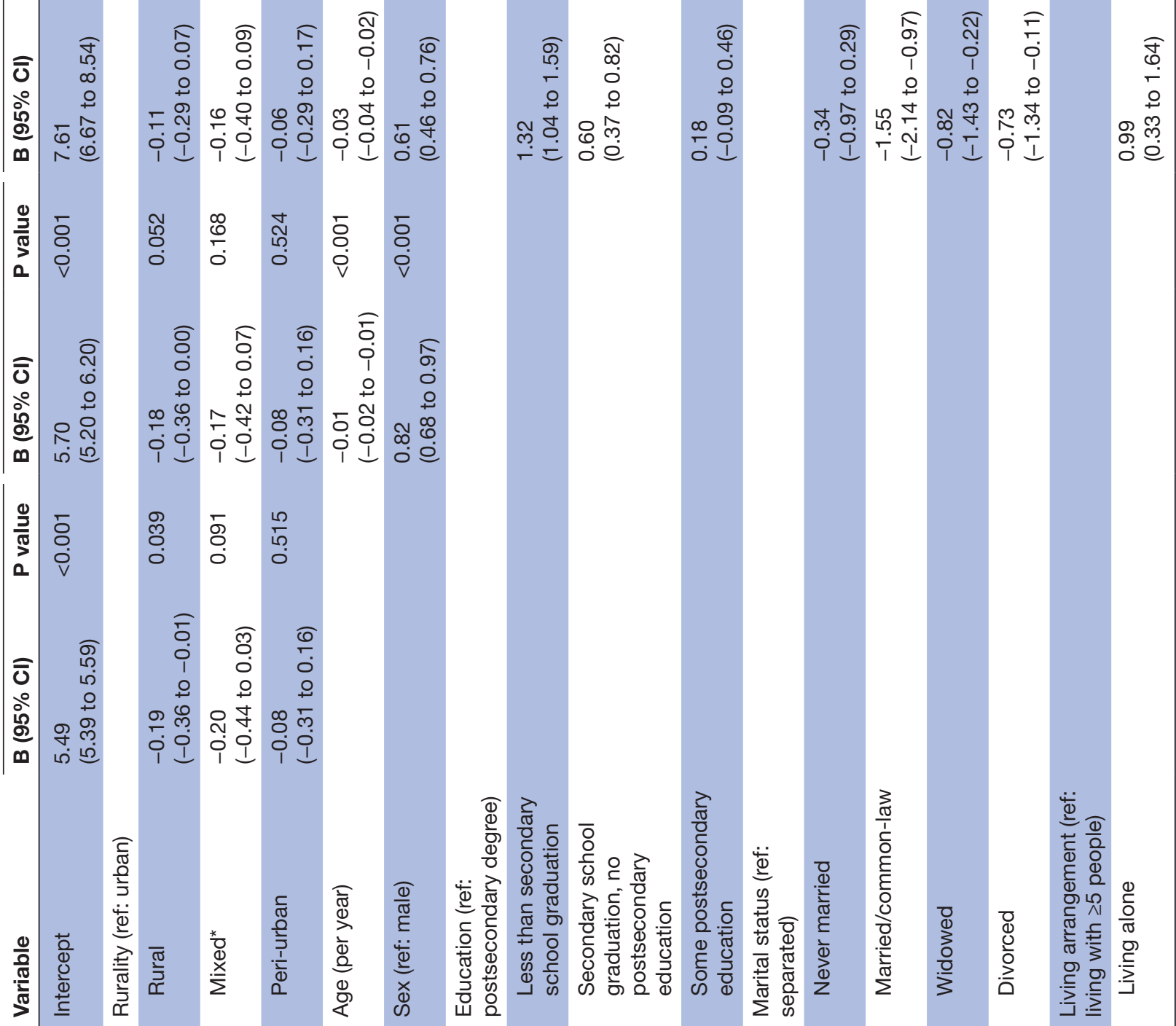


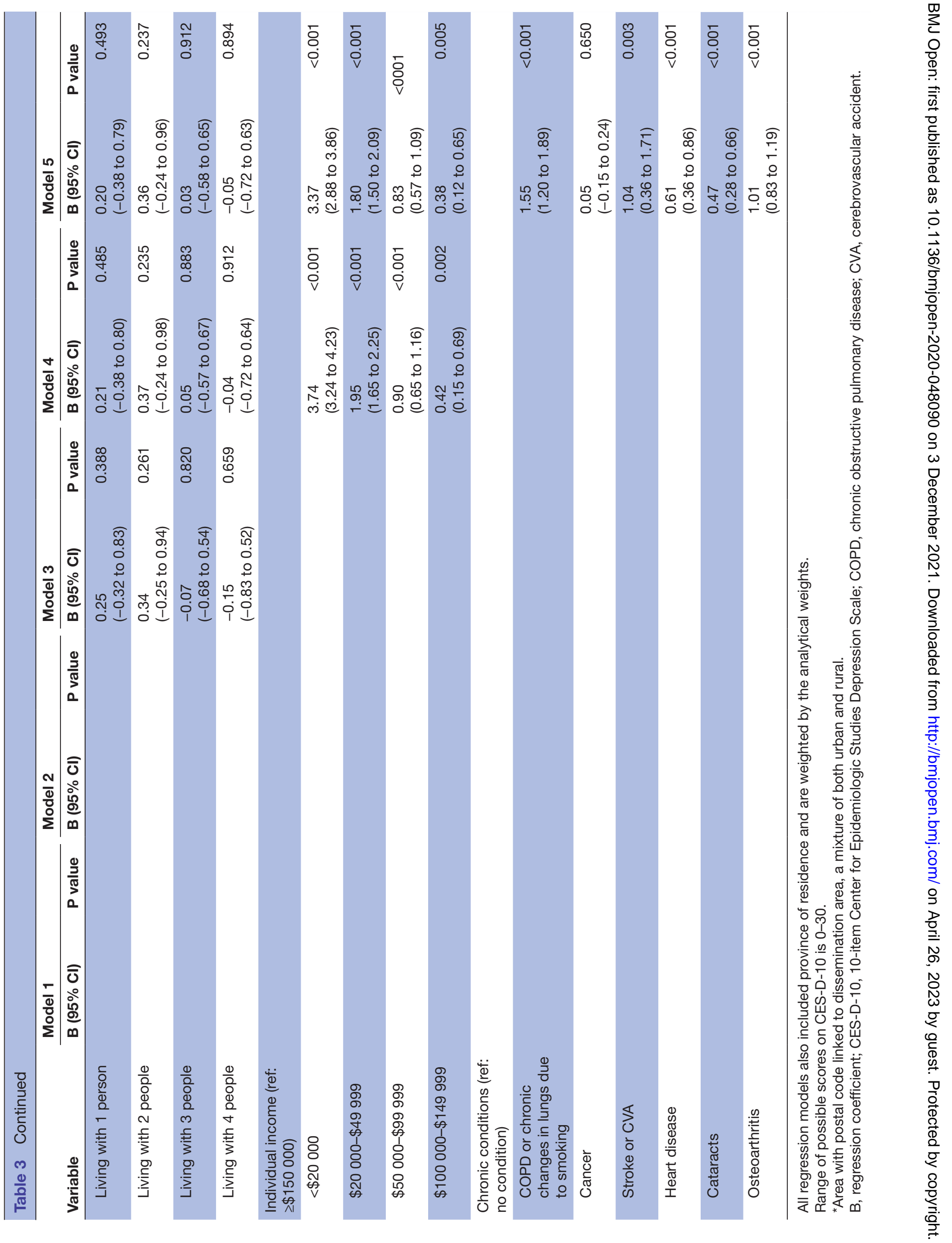




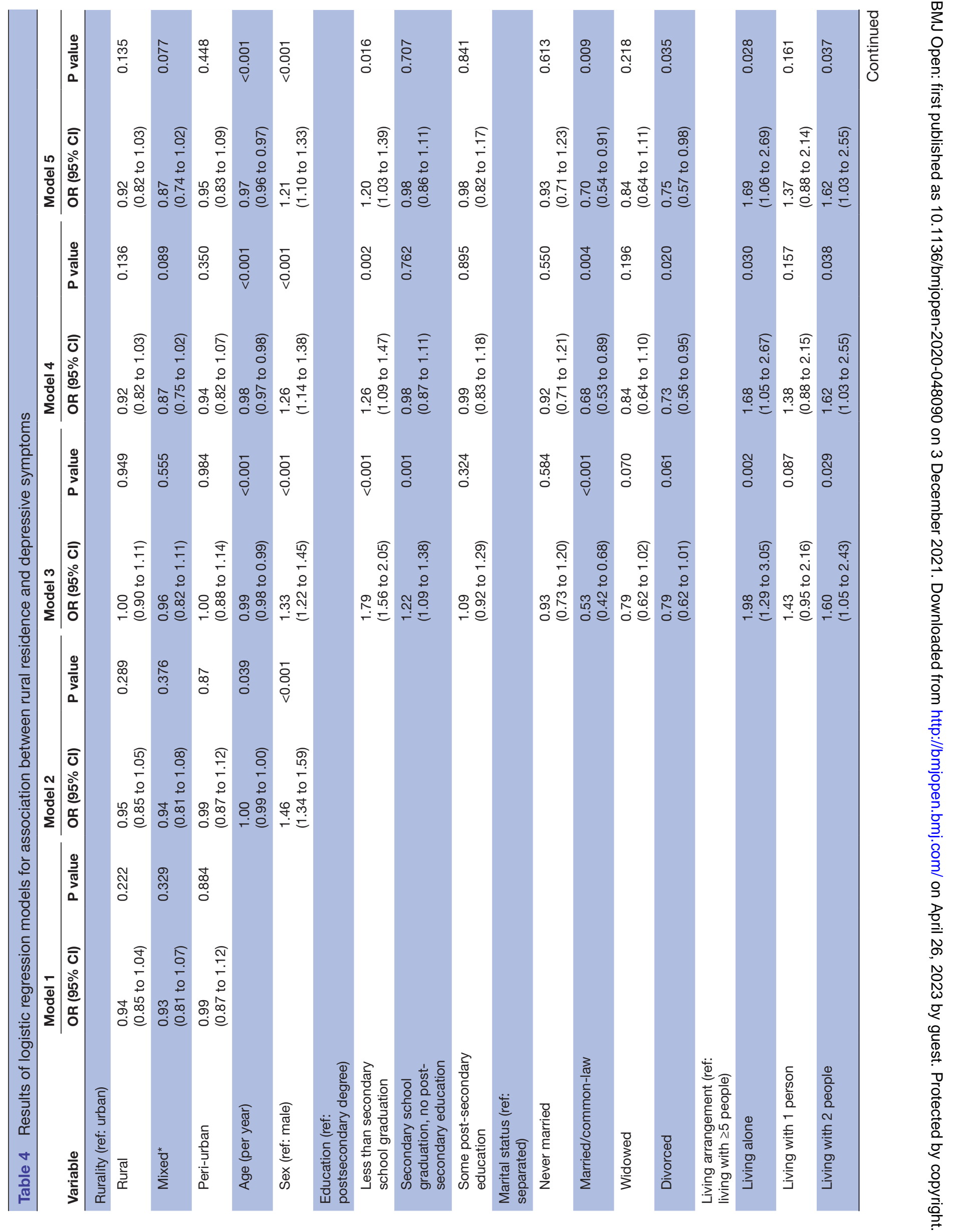




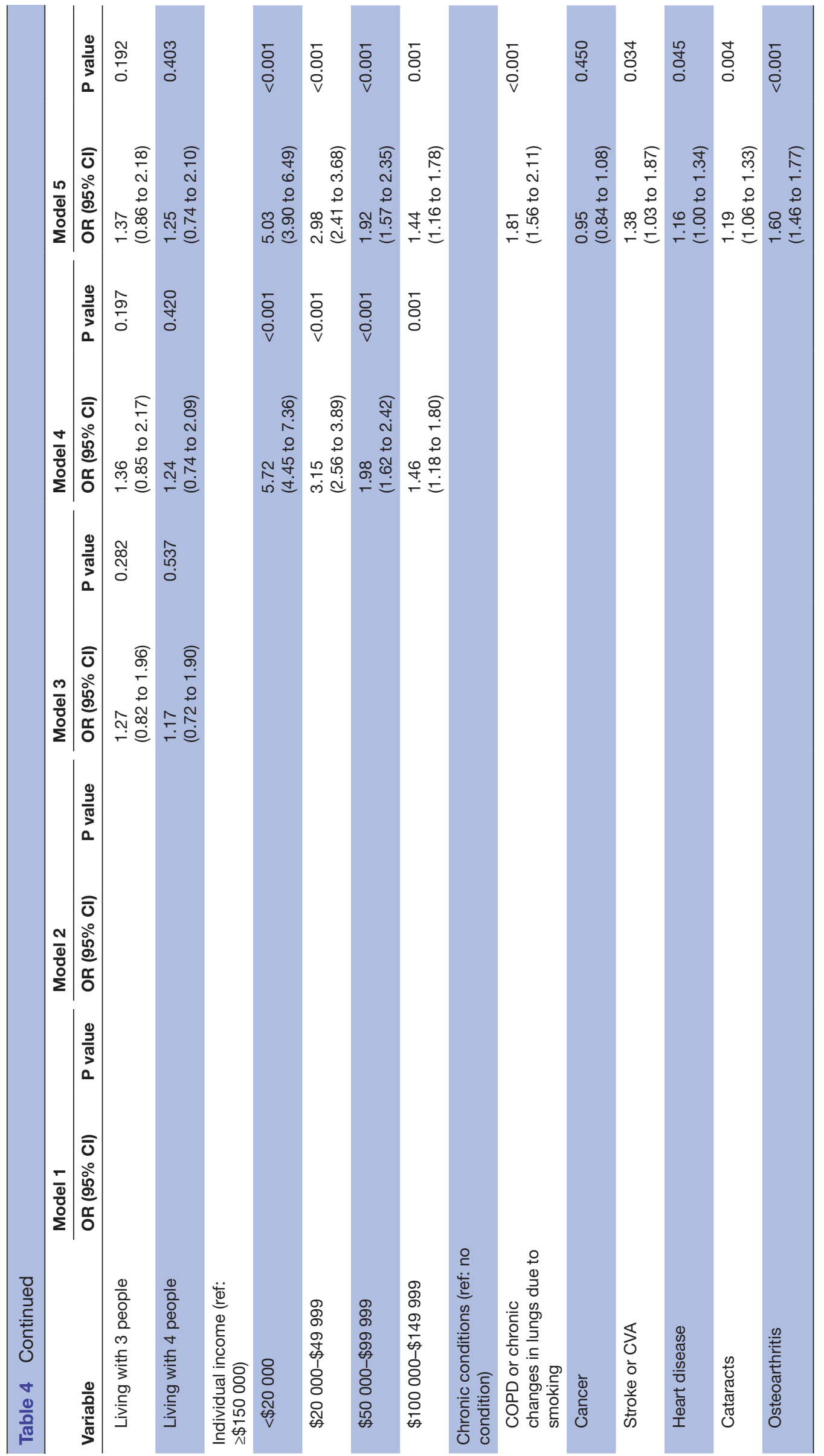


Author affiliations

${ }^{1}$ Geriatric Medicine, University of Manitoba, Winnipeg, Manitoba, Canada

${ }^{2}$ Community Medicine, University of Manitoba, Winnipeg, Manitoba, Canada

${ }^{3}$ Community Health Sciences, University of Manitoba, Winnipeg, Manitoba, Canada

${ }^{4}$ Psychology, Brandon University, Brandon, Manitoba, Canada

${ }^{5}$ Department of Geography and Institute on Aging and Lifelong Health, University of Victoria, Victoria, British Columbia, Canada

${ }^{6}$ Psychology, University of Saskatchewan, Saskatoon, Saskatchewan, Canada

Acknowledgements This research was made possible using the data collected by the Canadian Longitudinal Study on Aging (CLSA). Funding for the Canadian Longitudinal Study on Aging (CLSA) is provided by the Government of Canada through the Canadian Institutes of Health Research (CIHR) under grant reference: LSA 94473 and the Canada Foundation for Innovation. This research has been conducted using the CLSA dataset CLSA Baseline Tracking Dataset 3.4, under Application Number 19CA010. The CLSA is led by Drs. Parminder Raina, Christina Wolfson and Susan Kirkland. We thank all participants of the CLSA. We would also like to thank Ellen Shenk for administrative assistance and Scott Nowicki who conducted the analyses.

Contributors PDSJ: conceptualisation, methodology, formal analysis, investigation, resources, data curation, writing - original draft, visualisation, supervision, project administration, funding acquisition. VM: conceptualisation, methodology, data curation, writing - review and editing. RT: conceptualisation, methodology, writing - review and editing. NEN: conceptualisation, methodology, writing - review and editing. DC: conceptualisation, methodology, writing - review and editing. M0: conceptualisation, methodology, writing - review and editing, supervision. Scott Nowicki: formal analysis.PSJ:gaurantor.

Funding The contents of this study were developed under a Catalyst Grant (50240) from the Canadian Institutes of Health Research (CIHR). This research was made possible using the data collected by the Canadian Longitudinal Study on Aging (CLSA). Funding for the CLSA is provided by the Government of Canada through the ClHR under grant reference: LSA 94473 and the Canada Foundation for Innovation. This research has been conducted using the CLSA dataset CLSA Baseline Tracking Dataset 3.4, under Application Number 19CA010.

Disclaimer The opinions expressed in this manuscript are the author's own and do not reflect the views of the Canadian Longitudinal Study on Aging or the CIHR.

Competing interests PDSJ reports receiving a Catalyst Grant (50240) from the Canadian Institutes of Health Research for the conduct of the study. The other authors declare that there is no conflict of interest.

Patient and public involvement Patients and/or the public were not involved in the design, or conduct, or reporting, or dissemination plans of this research.

Patient consent for publication Consent obtained directly from patient(s)

Ethics approval Written informed consent was obtained from all participants before taking part in this study. Ethics approval for these analyses was granted by the University of Manitoba Bannatyne Campus Research Ethics Board (H2019:182 (HS22820)), and the study adheres to the Declaration of Helsinki. Participants were not involved in the design, or conduct, or reporting, or dissemination plans of our research.

Provenance and peer review Not commissioned; externally peer reviewed.

Data availability statement Data are available on reasonable request. Data are available from the Canadian Longitudinal Study on Aging (www.clsa-elcv.ca) for researchers who meet the criteria for access to de-identified CLSA data.Data may be obtained from a third party and are not publicly available.

Open access This is an open access article distributed in accordance with the Creative Commons Attribution Non Commercial (CC BY-NC 4.0) license, which permits others to distribute, remix, adapt, build upon this work noncommercially, and license their derivative works on different terms, provided the original work is properly cited, appropriate credit is given, any changes made indicated, and the use is non-commercial. See: http://creativecommons.org/ licenses/by-nc/4.0/.

\section{ORCID iDs}

Philip D St John http://orcid.org/0000-0002-8827-8220

Robert Tate http://orcid.org/0000-0002-0624-8264

Megan 0'Connell http://orcid.org/0000-0001-6159-4322

\section{REFERENCES}

1 Patten SB, Wang JL, Williams JVA, et al. Descriptive epidemiology of major depression in Canada. Can J Psychiatry 2006;51:84-90. doi:10.1177/070674370605100204

2 Koivumaa-Honkanen H, Kaprio J, Honkanen R, et al. Life satisfaction and depression in a 15-year follow-up of healthy adults. Soc Psychiatry Psychiatr Epidemiol 2004;39:994-9. doi:10.1007/s00127004-0833-6

3 Beekman ATF, Penninx BWJH, Deeg DJH, et al. The impact of depression on the well-being, disability and use of services in older adults: a longitudinal perspective. Acta Psychiatr Scand 2002;105:20-7. doi:10.1034/j.1600-0447.2002.10078.x

4 Deschênes SS, Burns RJ, Schmitz N. Associations between depression, chronic physical health conditions, and disability in a community sample: a focus on the persistence of depression. $J$ Affect Disord 2015;179:6-13. doi:10.1016/j.jad.2015.03.020

5 Cuijpers P, Smit F. Excess mortality in depression: a meta-analysis of community studies. J Affect Disord 2002;72:227-36.

6 Cuijpers P, Vogelzangs N, Twisk J, et al. Differential mortality rates in major and subthreshold depression: meta-analysis of studies that measured both. Br J Psychiatry 2013;202:22-7. doi:10.1192/bjp.bp. 112.112169

7 Cuijpers P, Vogelzangs N, Twisk J, et al. Comprehensive meta-analysis of excess mortality in depression in the general community versus patients with specific illnesses. Am J Psychiatry 2014:171:453-62. doi:10.1176/appi.ajp.2013.13030325

8 St John PD, Montgomery PR. Do depressive symptoms predict mortality in older people? Aging Ment Health 2009;13:674-81. doi:10.1080/13607860902774493

9 Louis W. Urbanism as a way of life. Am J Sociol 1938;44:1-24.

10 Hanlon N, Halseth G. The greying of resource communities in northern British Columbia: implications for health care delivery in already-underserviced communities. The Canadian Geographer/Le G?ographe canadien 2005;49:1-24.

11 Menec VH, Hutton L, Newall N, et al. How 'age-friendly' are rural communities and what community characteristics are related to age-friendliness? The case of rural Manitoba, Canada. Ageing Soc 2015;35:203-23. doi:10.1017/S0144686X13000627

12 Menec VH, Newall NE, Mackenzie CS, et al. Examining individual and geographic factors associated with social isolation and loneliness using Canadian longitudinal study on aging (CLSA) data. PLOS One 2019;14:e0211143. doi:10.1371/journal.pone.0211143

13 Routasalo PE, Savikko N, Tilvis RS, et al. Social contacts and their relationship to loneliness among aged people - a population-based study. Gerontology 2006;52:181-7. doi:10.1159/000091828

14 Savikko N, Routasalo P, Tilvis RS, et al. Predictors and subjective causes of loneliness in an aged population. Arch Gerontol Geriatr 2005;41:223-33. doi:10.1016/j.archger.2005.03.002

15 Alasia A, Rothwell N. The rural/urban divide is not changing: income disparities persist. Rural and Small Town Canada Analysis Bulletin 2003;4.

16 Singh V. The rural-urban income gap within provinces: an update to 2000. Rural and Small Town Canada Analysis Bulletin 2004;5.

17 Abrams LR, Mehta NK. Changes in depressive symptoms over age among older Americans: differences by gender, race/ethnicity, education, and birth cohort. SSM Popul Health 2019;7:100399. doi:10.1016/j.ssmph.2019.100399

18 Sareen J, Afifi TO, McMillan KA, et al. Relationship between household income and mental disorders: findings from a populationbased longitudinal study. Arch Gen Psychiatry 2011;68:419-27. doi:10.1001/archgenpsychiatry.2011.15

19 Lorant $\mathrm{V}$, Deliège $\mathrm{D}$, Eaton $\mathrm{W}$, et al. Socioeconomic inequalities in depression: a meta-analysis. Am J Epidemiol 2003;157:98-112. doi:10.1093/aje/kwf182

20 Pong RW, Desmeules M, Lagacé C. Rural-Urban disparities in health: how does Canada fare and how does Canada compare with Australia? Aust J Rural Health 2009;17:58-64. doi:10.1111/j.14401584.2008.01039.x

21 Mitura V, Bollman RD. The health of rural Canadians: a rural-urban comparison of health indicators. Rural and Small Town Canada Analysis Bulletin 2003;4.

22 Dandy K, Bollman RD. Seniors in rural Canada. Rural and Small Town Canada Analysis Bulletin 2008;7.

23 DesMeules M, Pong R, Lagacé C. How Healthy Are Rural Canadians? An Assessment of Their Health Status and Health Determinants. Ottawa, Ontario: Canadian Institute for Health Information, 2006

24 Weden MM, Shih RA, Kabeto MU, et al. Secular trends in dementia and cognitive impairment of U.S. rural and urban older adults. Am J Prev Med 2018;54:164-72. doi:10.1016/j.amepre.2017.10.021 
25 Schoeneberger ML, Leukefeld CG, Hiller ML, et al. Substance abuse among rural and very rural drug users at treatment entry. Am J Drug Alcohol Abuse 2006;32:87-110. doi:10.1080/00952990500328687

26 Rothwell N, Bollman RD, Tremblay J. Migration to and from rural and small town Canada. Rural and Small Town Canada Analysis Bulletin 2002;3.

27 von Reichert C, Berry EH. Rural-Urban patterns of disability: the role of migration. Popul Space Place 2019;1:1-18.

28 Keating N. Rural ageing: a good place to grow old? Bristol: Policy Press, 2008.

29 Winterton R, Warburton J. Does place matter? reviewing the experience of disadvantage for older people in rural Australia. Rural Soc 2011;20:187-97. doi:10.5172/rsj.20.2.187

30 Menec V, Bell S, Novek S, et al. Making rural and remote communities more age-friendly: experts' perspectives on issues, challenges, and priorities. J Aging Soc Policy 2015;27:173-91. doi:10 $.1080 / 08959420.2014 .995044$

31 Fried LP. Epidemiology of aging. Epidemiol Rev 2000;22:95-106. doi:10.1093/oxfordjournals.epirev.a018031

32 Schuster NA, Hoogendijk EO, Kok AAL, et al. Ignoring competing events in the analysis of survival data may lead to biased results: a nonmathematical illustration of competing risk analysis. J Clin Epidemiol 2020;122:42-8. doi:10.1016/j.jclinepi.2020.03.004

33 Wu Y-T, Prina AM, Barnes LE, et al. Relocation at older age: results from the cognitive function and ageing study. J Public Health 2015;37:480-7-7. doi:10.1093/pubmed/fdv050

34 Brown DL, Swanson LE. Challenges for rural America in the twentyfirst century. Pennsylvania State University Press, 2010.

35 St John PD, Blandford AA, Strain LA. Depressive symptoms among older adults in urban and rural areas. Int $J$ Geriatr Psychiatry 2006;21:1175-80. doi:10.1002/gps.1637

36 St John PD, Blandford AA, Strain LA. Does a rural residence predict the development of depressive symptoms in older adults? Can $J$ Rural Med 2009;14:150-6.

37 Wang JL. Rural-Urban differences in the prevalence of major depression and associated impairment. Soc Psychiatry Psychiatr Epidemiol 2004;39:19-25. doi:10.1007/s00127-004-0698-8

38 Mechakra-Tahiri S, Zunzunegui MV, Préville M, et al. Social relationships and depression among people 65 years and over living in rural and urban areas of Quebec. Int J Geriatr Psychiatry 2009;24:1226-36. doi:10.1002/gps.2250

39 Romans S, Cohen M, Forte T. Rates of depression and anxiety in urban and rural Canada. Soc Psychiatry Psychiatr Epidemiol 2011;46:567-75.

40 Purtle J, Nelson KL, Yang Y, et al. Urban-Rural differences in older adult depression: a systematic review and meta-analysis of comparative studies. Am J Prev Med 2019;56:603-13. doi:10.1016/j. amepre.2018.11.008

41 Raina P, Wolfson C, Kirkland S, et al. Cohort profile: the Canadian longitudinal study on aging (CLSA). Int J Epidemiol 2019;48:1752-3. doi:10.1093/ije/dyz173

42 Raina PS, Wolfson C, Kirkland SA, et al. The Canadian longitudinal study on aging (CLSA). Can J Aging 2009;28:221-9. doi:10.1017/ S0714980809990055

43 Raina PS, Wolfson C, Kirkland SA. The Canadian Longitudinal Study on Aging (CLSA): report on health and aging in Canada - findings from baseline data collection 2010-2015; 2018.

44 Kirkland SA, Griffith LE, Menec V, et al. Mining a unique Canadian resource: the Canadian longitudinal study on aging. Can J Aging 2015;34:366-77. doi:10.1017/S071498081500029X

45 Raina PS, Wolfson C, Kirkland SA. Canadian longitudinal study on aging (CLSA) protocol 2008.

46 Wolfson C, Raina PS, Kirkland SA, et al. The Canadian community health survey as a potential recruitment vehicle for the Canadian longitudinal study on aging. Can J Aging 2009;28:243-9. doi:10.1017/S0714980809990031

47 Plessis D V, Beshiri R, Bollman RD. Definitions of rural. Rural and Small Town Canada Analysis Bulletin 2001;3.

48 Statistics Canada. Canadian community health survey (CCHS): annual component, 2009-2010; common content; derived variable (dv) specifications, 2009
49 Statistics Canada. 2006 census dictionary, 2010. Minister of industry

50 Clark K, John PS, Menec V, et al. Healthcare utilisation among Canadian adults in rural and urban areas - The Canadian Longitudinal Study on Aging. Can J Rural Med 2021;26:69-79-79. doi:10.4103/CJRM.CJRM_43_20

51 John PS, Menec V, Tate R, et al. Functional status in rural and urban adults: the Canadian longitudinal study on aging. $J$ Rural Health 2021. doi:10.1111/jrh.12578. [Epub ahead of print: 22 Apr 2021].

52 Andresen EM, Malmgren JA, Carter WB, et al. Screening for depression in well older adults: evaluation of a short form of the CES-D (center for epidemiologic studies depression scale). Am J Prev Med 1994;10:77-84-84.

53 Radloff LS. The CES-D scale: a self-report depression scale for research in the general population. Appl Psychol Meas 1977:1:385-401. doi:10.1177/014662167700100306

54 Nishiyama T, Ozaki N, Iwata N. Practice-Based depression screening for psychiatry outpatients: feasibility comparison of two-types of center for epidemiologic studies depression scales. Psychiatry Clin Neurosci 2009;63:632-8. doi:10.1111/j.14401819.2009.02003.x

55 McDowell I. Measuring health: a guide to rating scales and questionnaires. Oxford University Press, 2006.

56 White J, Zaninotto P, Walters K, et al. Severity of depressive symptoms as a predictor of mortality: the English longitudinal study of ageing. Psychol Med 2015;45:2771-9. doi:10.1017/ S0033291715000732

57 Zhang W, O'Brien N, Forrest Jl, et al. Validating a shortened depression scale (10 item CES-D) among HIV-positive people in British Columbia, Canada. PLoS One 2012;7:e40793. doi:10.1371/ journal.pone.0040793

58 Björgvinsson T, Kertz SJ, Bigda-Peyton JS, et al. Psychometric properties of the CES-D-10 in a psychiatric sample. Assessment 2013;20:429-36. doi:10.1177/1073191113481998

59 Canadian Community Health Survey (CCHS). Canadian Longitudinal Study on Aging. Socio-demographic characteristics questionnaire (baseline). In: Statistics Canada. 4.2 on Healthy Aging, ed., 2018.

60 Haut ER, Pronovost PJ. Surveillance bias in outcomes reporting. JAMA 2011;305:2462-3.

61 Canadian longitudinal study on aging. chronic conditions tracking questionnaire (baseline) 2018.

62 St John PD, Montgomery PR. Marital status, partner satisfaction, and depressive symptoms in older men and women. Can J Psychiatry 2009;54:487-92. doi:10.1177/070674370905400710

63 Bulloch AGM, Williams JVA, Lavorato DH, et al. The depression and marital status relationship is modified by both age and gender. $J$ Affect Disord 2017;223:65-8. doi:10.1016/j.jad.2017.06.007

64 Bulloch AG, Williams JV, Lavorato $\mathrm{DH}$, et al. The relationship between major depression and marital disruption is bidirectional. Depress Anxiety 2009;26:1172-7. doi:10.1002/da.20618

65 Lavergne MR, Kephart G. Examining variations in health within rural Canada. Rural Remote Health 2012;12:1848.

66 Thiede BC, Monnat SM. The great recession and America's geography of unemployment. Demogr Res 2016;35:891-928. doi:10.4054/DemRes.2016.35.30

67 Beshiri R, Statistics Canada. Manufacturing employment in resource value chains: a rural-urban comparison from 2001 to 2008. Rural and Small Town Canada Analysis Bulletin 2010;8.

68 Menec VH, Nowicki S. Examining the relationship between communities' 'age-friendliness' and life satisfaction and selfperceived health in rural Manitoba, Canada. Rural Remote Health 2014:14:2594.

69 Federal, Provincial, Territorial Ministers Responsible for Seniors. AgeFriendly Rural and Remote Communities: A Guide. Ottawa: Minister of Industry, 2007.

70 Ryser L, Halseth G. Resolving mobility constraints impeding rural seniors' access to regionalized services. J Aging Soc Policy 2012;24:328-44.

71 Weeks WB, Wallace AE. Rural-Urban differences in primary care physicians' practice patterns, characteristics, and incomes. J Rural Health 2008;24:161-70. doi:10.1111/j.1748-0361.2008.00153.x 